\title{
Use of osteogenic protein-1 in spinal fusion: literature review and preliminary results in a prospective series of high-risk cases
}

\author{
Preneshlin V. Govender, M.B.Ch.B., F.C.S.(SA), Yoga R. RAMPERSAud, M.D., F.R.C.S.(C), \\ Lynda Rickards, R.N., and Michael G. FehlingS, M.D., F.R.C.S.(C), PH.D.
}

\author{
Spine Program, Divisions of Neurosurgery and Orthopaedic Surgery, University of Toronto, Toronto \\ Western Hospital, Toronto, Ontario, Canada
}

\begin{abstract}
Object. The safety and effectiveness of osteogenic protein (OP)-1 putty (recombinant human bone morphogenetic protein-7) in promoting fusion in complex spinal cases was studied in nine cases.

Methods. The authors prospectively evaluated nine patients requiring spinal fusion in whom there were medical risk factors that would inhibit osseous fusion. Intraoperatively the OP-1 putty mixed with autologous bone was placed at the fusion site. Outcome measurement instruments were used to provide information on patient demographics, comorbidities, and pain. The Short Form (SF)-36 questionnaire and Oswestry Disability Index (ODI) were administered pre- and postoperatively. All patients underwent routine radiography of the surgery site during follow-up examination.

The age of the five women and four men ranged from 21 to 74 years (mean height $1.6 \mathrm{~m}$, mean weight $76.7 \mathrm{~kg}$ ). Risk factors included mucopolysaccharide syndrome, adrenal insufficiency, rheumatoid arthritis with chronic corticosteroid use, morbid obesity, and heavy smoking. Surgery, which consisted of five cervical and four lumbar procedures, including intradural surgery in three patients, was uneventful in all cases without perioperative complication. The follow-up period ranged from 1 to 15 months (mean 5.22 months). The ODI score changed from severe disability (mean 46.89) preoperatively to minimal and moderate disability (mean 34.56) postoperatively. The SF-36 survey showed overall improved mental and physical health scores. Fusion was present in all patients with greater than 3 months follow up.

Conclusions. The OP-1 putty appears to be safe and effective in promoting spinal arthrodesis in patients in whom adverse medical risk factors exist.
\end{abstract}

\begin{abstract}
KEY WORDS • osteogenic protein-1 • spinal fusion • bone morphogenetic protein • bone graft
\end{abstract}

Autologous bone graft is still considered to be the gold standard against which new technologies are measured when assessing fusion rates in spinal surgery. Moreover, because anterior and posterior iliac crest bone graft harvesting therefore continues to be frequently performed, persisting bone graft pain has been reported at long term follow up in over $15 \%$ of patients despite successful fusion surgery. ${ }^{14}$ It is also therefore not uncommon for patients to be completely satisfied with their outcomes but continue to be unhappy about iliac crest donor-site problems. Donor site complications, both major and minor, are now being more closely examined as overall spinal surgery-associated morbidity rates are being improved. Although complication rates are reduced with the advances in surgical technique and the knowledge of donor-site anatomy, the only way to avoid complications completely in this area is to avoid harvesting the bone graft.

Abbreviations used in this paper: $\mathrm{BMP}=$ bone morphogenetic protein; $\mathrm{DBM}=$ demineralized bone matrix; ODI = Oswestry Disability Index; SF-36 = Short Form-36.
Modern spinal instrumentation devices are magnetic resonance imaging compatible, easier to use, and more durable than early hardware. This, however, has not changed the fact that in the time it takes for spinal fusion to occur, there is the risk of hardware failure or breakage. Fusion continues to be dictated by biological principles, and only a biological environment conducive to bone formation and consolidation will allow a successful osseous arthrodesis to occur. As a result researchers at most modern laboratories have focused on molecular biology research and the development of osteoinductive growth factors. These biological growth factors have been purified and further developed since they were first isolated in the late 1960s from bone in a partially purified form. Bone morphogenetic proteins are one such group of growth factors that function by inducing transformation of undifferentiated pluripotent mesenchymal cells into chondroblasts and osteoblasts and eventually resulting in the formation of de novo bone. ${ }^{31}$ The BMP-7 also known as OP-1 has been shown to promote bone fusion in animal studies, but is still being fully evaluated in human trials. ${ }^{10,31}$ 
To evaluate the effectiveness of BMPs in spinal fusion, we present our preliminary experience with the use of OP-1 to enhance arthrodesis in high-risk patients undergoing spinal fusion. To facilitate bone fusion, favorable local and systemic factors must be present. Systemic comorbidities, such as nicotine abuse and metabolic disorders, affect proper vascular ingrowth to the fusion site and therefore compromise fusion. ${ }^{31}$ If bone fusion and patient outcome are enhanced by BMPs, even in these unfavorable situations, then its use may be a welcomed addition to modern spinal fusion surgery.

\section{CLINICAL MATERIAL AND METHODS}

Patients who required spinal fusion procedures underwent relevant preoperative radiological imaging. Those in whom medical risk factors were identified that would inhibit spinal fusion were considered for enrollment in the study. Patients were counseled by surgical and nursing staff about the effect of OP-1 to augment the fusion process.

\section{Patient Population}

The study group consisted of nine patients, five women and four men, who required spinal fusion surgery (five cervical and four lumbar). The mean age of the patients was 47 years (range 21-74 years), mean weight was 76.71 $\mathrm{kg}$ (range 40.91-136.36 kg), and the mean height was $1.64 \mathrm{~m}$ (range 1.52-1.83 m) (Tables 1-3). Patients were followed for 2 to 15 months postoperatively (mean 5.22 months).

The Musculoskeletal Outcomes Data Evaluation and Management System questionnaire, which included details of patient demographics and medical comorbidities, was used to evaluate patients preoperatively. The questionnaire also included the SF-36 survey and the ODI survey. ${ }^{12,32,33}$

During routine spinal surgery, the OP-1 putty (3.5 mg of osteogenic material with collagen carrier and $2.5 \mathrm{ml}$ of sterile saline) was mixed with autologous bone harvested from the iliac crest and/or from the site of the local spinal decompression.

Routine postoperative rehabilitation was undertaken, and patients were followed as outpatients. During follow up, patients were assessed clinically and by routine plain radiography of the surgical site. Patients also complet- ed the Musculoskeletal Outcomes Data Evaluation and Management System questionnaire with SF-36 and ODI surveys at each outpatient clinic visit.

The values generated by the SF-36 survey were used to obtain scores for the eight different scales of physical and mental health: Physical Functioning, Role-Physical, Bodily Pain, General Health, Vitality, Social Functioning, Role-Emotional, and Mental Health. The ODI was calculated for each patient. All values obtained postoperatively were compared with those obtained preoperatively (Tables $2 \& 3$ ).

The radiographs were routinely analyzed, using the criteria of Blount, et al. ${ }^{4}$ for presence of a fusion mass at the surgical site, the presence of intact spinal fixation devices, and the absence of movement on dynamic flexion-extension $\mathrm{x}$-ray films.

\section{RESULTS}

\section{Case 1}

This patient was known to have a mucopolysaccharide deficiency syndrome and complained mainly of neck pain and generalized arthralgia. Craniocervical decompression and fixation were performed. Postoperatively his ODI score decreased and only his Role-Physical and Social Functioning scores decreased because of his long-term rehabilitation and ongoing medical problems. Radiography performed 5 months postoperatively demonstrated evidence of bone fusion.

\section{Case 2}

This patient had previously seen a chiropractor and physiotherapist for his low-back pain with no response and now required lumbar decompressive surgery and pedicle screw fixation. Postoperatively, however, his ODI score reflected a worsened condition, and scores in all scales of the SF-36 survey were lower. This poor result was directly due to myelopathy that developed secondary to unrelated cervical spondylosis, which subsequently required cervical. His low-back symptoms, however, had resolved and lumbar radiography revealed evidence of fusion at 3 months postoperatively (Fig. 1).

\section{Case 3}

This patient required a suboccipital decompression, duraplasty, and occipitocervical fusion. Postoperatively his

TABLE 1

Summary of preoperative characteristics in nine patients

\begin{tabular}{|c|c|c|c|c|c|}
\hline $\begin{array}{l}\text { Case } \\
\text { No. }\end{array}$ & $\begin{array}{c}\text { Age (yrs), } \\
\text { Sex }\end{array}$ & $\begin{array}{c}\text { Height } \\
(\mathrm{m})\end{array}$ & $\begin{array}{l}\text { Weight } \\
\text { (kg) }\end{array}$ & Comorbidities & Spinal Disease \\
\hline 1 & $21, \mathrm{M}$ & 1.52 & 46.82 & Maroteaux-Lamy syndrome & C1-2 instability, craniocervical stenosis \\
\hline 2 & $52, \mathrm{M}$ & 1.80 & 136.36 & obesity, hypertension, heavy smoker, Jehovah's Witness & lumbar spodylolisthesis and stenosis \\
\hline 3 & $37, \mathrm{M}$ & 1.59 & 40.91 & adrenal insufficiency, osteoporosis & Chiari I malformation \& basilar invagination \\
\hline 4 & $58, \mathrm{~F}$ & 1.52 & 63.64 & hypothyroidism, heavy smoker & lumbar spondylolisthesis \& stenosis \\
\hline 5 & $27, \mathrm{~F}$ & 1.57 & 41.36 & osteoporosis & lumbar spondylolisthesis \& tethered cord syndrome \\
\hline 6 & $36, \mathrm{~F}$ & 1.75 & 95.45 & rheumatoid arthritis & $\mathrm{C} 1-2$ instability \\
\hline 7 & $74, \mathrm{M}$ & 1.83 & 79.55 & hypothyroidism, atrial fibrillation, epilepsy, heavy smoker & $\mathrm{C} 1-2$ fracture \\
\hline 8 & $53, \mathrm{M}$ & 1.68 & 113.64 & obesity, heavy smoker & Chiari I malformation \& basilar invagination \\
\hline 9 & $65, \mathrm{~F}$ & 1.53 & 72.73 & rheumatoid arthritis & failed lumbar fusion \\
\hline
\end{tabular}


TABLE 2

Oswestry Disability Index

\begin{tabular}{ccc}
\hline \hline & \multicolumn{2}{c}{ ODI Score } \\
\cline { 2 - 3 } Case No. & Preop & Postop \\
\hline 1 & 33 & 20 \\
2 & 38 & 87 \\
3 & 33 & 0 \\
4 & 43 & 9 \\
5 & 53 & 25 \\
6 & 43 & 35 \\
7 & 56 & 30 \\
8 & 63 & 51 \\
9 & 60 & 54 \\
\hline
\end{tabular}

ODI score decreased to zero; however, his Physical Functioning, Bodily Pain, and Social Functioning scores decreased because he was required to undergo halo vest immobilization for 3 months. Radiography thereafter demonstrated evidence of fusion and no features of instability.

\section{Case 4}

This patient received unsuccessful treatment by a chiropractor, acupuncturist, message therapist, and physiotherapist. She required lumbar decompression, posterior lumbar interbody fusion, and pedicle screw fixation. At 2 months postoperatively her ODI score decreased; however, her General Health, Vitality, Social Functioning, and Mental Health scores were lower. The rest of the scores had improved, and her low-back and leg pain had also improved.

\section{Case 5}

This patient required spinal cord untethering and lumbar pedicle screw fixation. Postoperatively her ODI score decreased, and none of the SF-36 scores decreased. Dynamic radiosurgery at 6 months revealed evidence of a fusion mass and stability.

\section{Case 6}

This patient required atlantoaxial stabilization. At 2-month follow up, her disability, reflected by the ODI score, improved. Despite lower Physical Functioning and Social Functioning scores, scores in the remaining SF-36 domains improved.

\section{Case 7}

This patient required cervical laminectomy and occipitocervical fusion. Postoperatively after an initial improvement up to 6 months, his condition started to deteriorate at 15 months because of further spinal cord compression, which responded successfully to further surgical intervention.

\section{Case 8}

This patient required suboccipital decompression, duraplasty, and occipitocervical fusion. A cerebrospinal fluid leak developed postoperatively which resolved after insertion of a temporary lumbar spinal drain. His ODI score and Physical Functioning, Bodily Pain, and Mental Health scores improved at 2-month follow-up examination.

\section{Case 9}

This patient required a lumbar pedicle subtraction osteotomy and pedicle screw fixation. Although her RoleEmotional score did not improve, the remaining SF-36 scores did, and at 3-month follow up her ODI score was similar to the preoperative score.

\section{DISCUSSION}

Overall complication rates associated with harvesting bone graft range from 7.4 to $49 \%$. $^{2,3,5,9,15,16,18,23,27,28}$ Some complications associated with iliac crest bone harvesting include pain, neural injury, vascular injury, cosmetic deformity, hematoma formation, infection, gait problems, fractures, ureteric injury, hernia, sacroiliac joint instability, and peritoneal perforation. Donor-site pain persisting for more than 3 months has been reported in up to $15 \%$ of the relevant cases with no apparent difference in the incidence of anterior and posterior wounds; additionally the amount of pain seems to be proportional to the amount of dissection needed to obtain the bone graft. ${ }^{18}$ Common neural injuries include the lateral femoral cutaneus and the ilioinguinal nerves when anterior iliac crest harvesting is performed and the superior cluneal nerves when posterior

TABLE 3

Pre- and postoperative SF-36 domain scores*

\begin{tabular}{ccccccccc}
\hline \hline \multicolumn{3}{c}{ Preop/1st Postop SF-36 Score } & & & & & & \\
Case No. & PF & RP & BP & GH & VT & SF & RE & MH \\
\hline 1 & $10 / 35$ & $50 / 25$ & $31 / 42$ & $47 / 47$ & $25 / 25$ & $50 / 25$ & $33.3 / 33.3$ & $32 / 48$ \\
2 & $50 / 25$ & $0 / 0$ & $30 / 0$ & $40 / 20$ & $6 / 25$ & $50 / 0$ & $100 / 0$ & $60 / 44$ \\
3 & $75 / 55$ & $0 / 0$ & $80 / 21$ & $62 / 62$ & $45 / 65$ & $100 / 37.5$ & $100 / 100$ & $64 / 88$ \\
4 & $35 / 45$ & $0 / 0$ & $22 / 42$ & $100 / 82$ & $60 / 50$ & $12.5 / 37.5$ & $33.3 / 33.3$ & $72 / 60$ \\
5 & $25 / 35$ & $0 / 0$ & $52 / 52$ & $30 / 35$ & $20 / 40$ & $25 / 62.5$ & $0 / 100$ & $36 / 64$ \\
6 & $65 / 55$ & $0 / 0$ & $22 / 62$ & $62 / 72$ & $20 / 40$ & $50 / 25$ & $0 / 66.7$ & $56 / 68$ \\
7 & $5 / 20$ & $0 / 25$ & $62 / 41$ & $72 / 57$ & $40 / 40$ & $50 / 62.5$ & $0 / 100$ & $72 / 80$ \\
8 & $10 / 15$ & $0 / 0$ & $12 / 21$ & $50 / 35$ & $35 / 20$ & $37.5 / 25$ & $0 / 0$ & $56 / 68$ \\
9 & $5 / 20$ & $0 / 0$ & $10 / 31$ & $5 / 45$ & $0 / 25$ & $12.5 / 50$ & $100 / 0$ & $60 / 64$ \\
\hline
\end{tabular}

* $\mathrm{BP}$ = bodily pain; $\mathrm{GH}=$ general health; $\mathrm{MH}=$ mental health; $\mathrm{PF}=$ physical functioning; $\mathrm{RE}=$ role-emotional; $\mathrm{RP}=$ role-physical; $\mathrm{SF}=$ social functioning; $\mathrm{VT}=$ vitality. 
iliac crest harvesting is performed. The superior gluteal artery, as it enters the gluteal region through the sciatic notch, is commonly injured. If transected, the severed artery often retracts into the pelvis and continues to bleed. Cosmetic deformity has been a problem in thinner patients, and various techniques of harvesting the bone graft have been proposed to preserve the normal contour of the iliac crest. Blood loss and hematoma formation are wellrecognized complications, more commonly association with anterior iliac crest harvesting. This difference between anterior and posterior sites has been attributed to the pressure applied on posterior wounds while patients lay supine. The incidence of hematoma reported in recent literature has decreased with suction drainage and the use of hemostatic agents such as bone wax and thrombinsoaked Gelfoam. Infection rates have also decreased in relation to the reduction in hematoma rates.

Because of these common and wide-ranging possible complications, it is not surprising to find that numerous other options, including allograft and various synthetic compounds, have been used to promote fusion. Because researchers are concentrating on alternatives to autologous bone graft, these donor-site complications will not be an issue once bone graft harvesting is no longer needed.

Two promising alternatives include DBM grafts and BMP, which are part of the transforming growth factor $-\beta$ superfamily based on primary amino acid sequence homology. Through molecular cloning more than 20 related members have been identified to date (for example, BMP7) with six of these appearing to be structurally related and

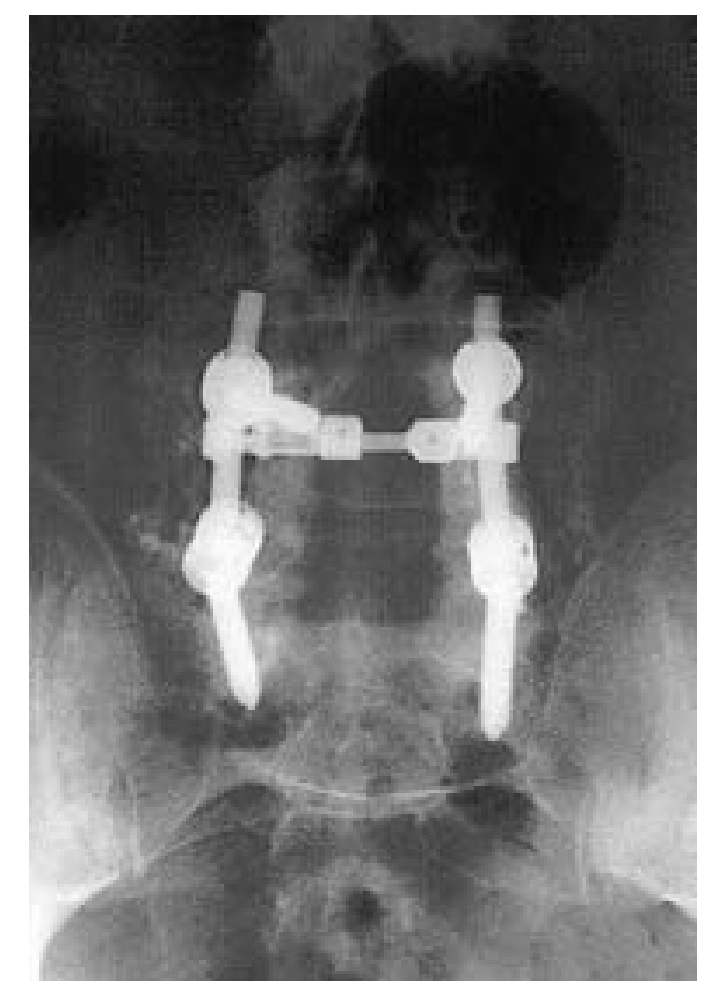

Fig. 1. Plain anteroposterior radiograph of the lower lumbar spine, demonstrating the presence of intact instrumentation and a lateral bone fusion mass. capable of endochondral bone formation. Some tissue growth factors, such platelet-derived growth factor, allow for tissue repair by encouraging the expression of the cell phenotype in already differentiated cells. The use of BMPs, however, seems to stimulate undifferentiated pluripotent cells to initiate the bone-forming cascade. . $^{16,26,29,30}$

Through genetically modified cell lines, recombinant BMPs have been produced as singular molecular species in unlimited quantities. These proteins have the benefit of not inducing a host-graft immune response and are free of infectious agents and contaminants. These proteins are soluble molecules, however, and if implanted alone diffuse too rapidly to allow osteoinduction. An optimal vehicle or carrier is needed. This carrier must allow a controlled release of the protein; provide adequate exposure to the inducible cells; be biocompatible with host tissues; have an architecture conducive to rapid ingrowth of newly formed bone; and have load bearing properties in certain fusion situations.

Demineralized bone matrix has been shown to have bone-inductive activity, and the primary osteoinductive component is a series of low-molecular weight glycoproteins that include the BMPs. Decalcification of cortical bone exposes these osteoinductive factors. By demineralizing the bone, the antigenic material is destroyed and is therefore less immunogenic than mineralized bone allograft. Additionally DBM has been shown to possess osteoconductive mechanisms, and the authors of animal studies have demonstrated that it is a graft enhancer, extender, and in some instances substitute. ${ }^{26}$ Also in animal studies DBM with autologous bone marrow has been shown to be as good as autograft when fusion masses were assessed by palpation and histological, radiographic, and biomechanical analyses. ${ }^{26}$ Boden and colleagues ${ }^{5-8}$ have also assessed other forms of DBM, such as gel DBM (particulate based), flex DBM (fiber based), and putty DBM (malleable consistency), as well as BMP in different spinal fusion models. They demonstrated that gel DBM with autograft in a ratio of 3:1 yields the best results. The extraction of guanidine from the DBM has also been shown to devitalize the DBM.

Most studies in which investigators assessed DBM involved simple anterior and posterior fusions. Posterolateral fusions, however, are more challenging. Boden and coworkers $^{6,7}$ were able to demonstrate a high fusion rate after conducting posterolateral fusion in rabbit models. The authors of other studies, however, have shown DBM to be less optimal than as autograft in certain animal and nonhuman primate fusion models. In one such study ${ }^{17}$ investigators found low fusion rates and an inhibitory effect on fusion associated with DBM.

Bioceramics such as sea coral and hydroxyapatite have also been evaluated, although their effects have been shown to be less optimal than autograft. ${ }^{2,5}$ If used with DBM, however, they may be as effective as autograft in certain cases.

Bone morphogenetic proteins are thought to be the solution to these problems in the search for an alternative to bone autograft.

The OP-1 (BMP-7) recruits stem cells from surrounding blood supply and tissue such as muscle and periosteum by chemotaxis, stimulating the cells and creating an environment in which they multiply and then differentiate. 
The protein does this by attaching to specific receptors on the cells surface that in turn transmit the message to the cell nucleus via intracellular proteins such as Smads. The bone-forming cascade is then initiated. Thus, BMP is osteopromotive, -inductive, and -conductive.

We focus the following review on recent studies involving BMP-2 and -7 in animal and clinical settings. These two proteins differ in that their collagen carriers are derived from different tissues.

In a canine model, Helm and coworkers ${ }^{17}$ performed unilateral lumbar decompressions and contralateral fusion involving DBM, BMP-2, and Type I collagen gels. The surgery was performed to reproduce that conducted in patients with spinal stenosis and unilateral radicular symptoms. Volumetric, histological, and biomechanical analyses were used to assess the fusion mass. Whereas DBM had an inhibitory effect on bone fusion, BMP-2 enhanced bone deposition and increased the number of fused levels. Type I collagen improved the graft-host interface.

Recombinant BMP-2 was used for posterolateral fusion in a rabbit model by Schimandle, et al. ${ }^{27}$ Radiologically and histologically, greater and more rapid bone formation, consolidation, and remodeling were shown with recombinant human BMP-2 compared with autologous bone grafts. Sandhu, et al., ${ }^{25}$ evaluated different doses of BMP-2 in a canine model of lumber intertransverse fusion. No mechanical, radiographic, or histological differences in the quality of fusion resulted from a 40-fold variation in dose.

Alden, et al., ${ }^{1}$ demonstrated percutaneous spinal fusion in rats by direct injection of an adenoviral construct containing the $B M P-2$ gene. They found that it is possible to produce in vivo endochondral bone formation by using direct adenoviral construct injection into the paraspinal musculature. This result suggests that gene therapy may be useful for spinal fusions in the future.

Recombinant human OP-1 (BMP-7) was used as a bone graft substitute in adult mongrel dogs in which posterior spinal fusions was conducted. ${ }^{9}$ Cook and colleagues ${ }^{9}$ found radiological and histological stable fusions the study group by 6 weeks and that complete fusion was evident by 12 weeks postimplantation. In the control group (autograft) fusion was demonstrated at 26 weeks.

Salkeld, et al., ${ }^{24}$ demonstrated that OP-1 was as effective as autograft in a canine study in which they treated segmental ulnar defects. A similar result was obtained by Friedlaender and coworkers ${ }^{13}$ in a prospective randomized clinical trial to treat tibial nonunions.

Magin and Delling ${ }^{20}$ used recombinant human OP-1 for interbody fusion in a sheep model. Analysis of their results showed that the study group developed superior fusion compared with the autograft-treated control group.

Grauer, et al., ${ }^{15}$ used BMP-7 for intertransverse fusion in a rabbit model. They found higher and earlier fusion rates than those in the control group treated with autograft. Bovine-derived osteoinductive growth factor was used by Boden, et al., ${ }^{6}$ for posterolateral spinal fusions in a rabbit model and a nonhuman primate model. Different doses and carrier materials (autologous bone, DBM, and natural coral) were also used. They found a dose-dependent response to the osteoinductive growth factor in the rabbit model, indicating that a threshold must be overcome be- fore bone formation is induced. The same group of investigators had also developed an animal model for intertransverse spinal fusion to allow closer replication of the human procedure in surgical technique, graft healing environment, and outcome. ${ }^{7}$

In another study from the same department, investigators assessed BMP-2 and a hydroxyapatite-tricalcium phosphate carrier as a complete graft substitute for intertransverse spinal fusion in adult rhesus monkeys. ${ }^{5}$ Different doses of BMP-2 were used. Fusion was not achieved in the monkeys treated with autologous iliac crest graft, whereas all BMP-2-treated monkeys, in all dose groups, achieved solid fusion. There was no evidence of bone induction outside the confines of the ceramic carrier. The same authors later performed a prospective randomized controlled human clinical pilot trial to assess the use of BMP-2 in interbody fusion cages. ${ }^{8}$ Arthrodesis was found to occur more reliably in patients treated with BMP-2filled fusion cages than in autologous bone graft-treated controls, although the sample size was limited. There were no adverse effects related to the BMP-2 treatment.

The authors of an endoscopic interbody fusion study in a sheep model reported a statistically higher segmental biomechanical stiffness levels compared with the control group. ${ }^{11}$ The fusion mass in the study group showed histomorphometric equivalency to autologous fusions.

In a pilot clinical trial involving BMP-7-treated patients with thoracolumbar burst fractures, the authors' preliminary results regarding BMP-7 as a bone graft were disappointing. ${ }^{19}$ The BMP-7-treated device was not capable of inducing an early sufficient structural bone support.

Patel and colleagues ${ }^{22}$ proved that OP-1 overcomes the inhibitory effects of nicotine in a posterolateral fusion study in a rabbit model.

In another study, Paramore, et al., ${ }^{21}$ intentionally placed BMP-7 in the subarachnoid space in dogs, which resulted in subarachnoid bone formation. These authors showed that morphogenetic proteins must be carefully controlled to avoid unwanted bone formation and subsequent neural compression.

In our study of OP-1 in the nine high-risk patients with spinal lesions, we observed no adverse effects related to this protein. Evidence of bone fusion was demonstrated in these patients despite their complex medical problems, including smoking, which is a well-known inhibitor of bone fusion. A prospective controlled randomized trial involving a larger number of patients is needed before OP-1 can be considered part of the standard treatment in spinal fusion.

\section{CONCLUSIONS}

Preliminary results with the use of BMPs in spinal fusion are encouraging. The necessity to harvest autologous bone graft may become rare in the near future. Osteogenic protein-1 appears to be safe and effective in promoting spinal arthrodesis, even in patients with adverse medical risk factors.

\section{Disclaimer}

Although OP-1 has not been Federal Drug Administration approved for use in spinal fusion, it has received investigational status. 


\section{References}

1. Alden TD, Pittman DD, Beres EJ, et al: Percutaneous spinal fusion using bone morphogenetic protein-2 gene therapy. J Neurosurg (Spine 1) 90:109-114, 1999

2. Arrington ED, Smith WJ, Chambers HG, et al: Complications of iliac crest bone graft harvesting. Clin Orthop 329:300-309, 1996

3. Banwart JC, Asher MA, Hassanein RS: Iliac crest bone graft harvest donor site morbidity. A statistical evaluation. Spine 20: 1055-1060, 1995

4. Blount KJ, Krompinger WJ, Maljanian R, et al: Moving toward a standard for spinal fusion outcomes assessment. J Spinal Disord Tech 15:16-23, 2002

5. Boden SD, Martin GJ Jr, Morone MA, et al: Posterolateral lumbar intertransverse process spine arthrodesis with recombinant human bone morphogenetic protein 2 /hydroxyapatite-tricalcium phosphate after laminectomy in the nonhuman primate. Spine 24:1179-1185, 1999

6. Boden SD, Schimandle JH, Hutton WC: An experimental lumbar intertransverse process spinal fusion model. Radiographic, histologic, and biomechanical healing characteristics. Spine 20:412-420, 1995

7. Boden SD, Schimandle JH, Hutton WC: 1995 Volvo Award in basic sciences. The use of an osteoinductive growth factor for lumbar spinal fusion. Part II: study of dose, carrier, and species. Spine 20:2633-2644, 1995

8. Boden SD, Zdeblick TA, Sandhu HS, et al: The Use of rhBMP2 in interbody fusion cages. Definitive evidence of osteoinduction in humans: a preliminary report. Spine 25:376-381, 2000

9. Cook SD, Dalton JE, Tan EH, et al: In vivo evaluation of recombinant human osteogenic protein (rhOP-1) implants as a bone graft substitute for spinal fusions. Spine 19:1655-1663, 1994

10. Cook SD, Wolfe MW, Salkeld SL, et al: Effect of recombinant human osteogenic protein-1 on healing of segmental defects in non-human primates. J Bone Joint Surg Am 77:734-750, 1995

11. Cunningham BW, Kanayama M, Parker LM, et al: Osteogenic protein versus autologous interbody arthrodesis in the sheep thoracic spine. A comparative endoscopic study using the Bagby and Kuslich interbody fusion device. Spine 24:509-518, 1999

12. Fairbank JC, Couper J, Davies JB, et al: The Oswestry low back pain disability questionnaire. Physiotherapy 66:271-273, 1980

13. Friedlaender GE, Perry CR, Cole JD, et al: Osteogenic protein1 (bone morphogenetic protein-7) in the treatment of tibial nonunions. J Bone Joint Surg Am 83 (Suppl 1):151-158, 2001

14. Gibson S, McLeod I, Wardlaw D, et al: Allograft versus autograft in instrumented posterolateral lumbar spinal fusion: a randomized control trial. Spine 27:1599-1603, 2002

15. Grauer JN, Patel TC, Erulkar JS, et al: 2000 Young Investigator Research Award Winner. Evaluation of OP-1 as a graft substitute for intertransverse process lumbar fusion. Spine 26: 127-133, 2001

16. Hecht BP, Fischgrund JS, Herkowitz HN, et al: The use of recombinant human bone morphogenetic protein 2 (rhBMP-2) to promote spinal fusion in a nonhuman primate anterior interbody fusion model. Spine 24:629-636, 1999

17. Helm GA, Sheehan JM, Sheehan JP, et al: Utilization of type I collagen gel, demineralized bone matrix, and bone morphogenetic protein-2 to enhance autologous bone lumbar spinal fusion. J Neurosurg 86:93-100, 1997
18. Kurz LT, Garfin SR, Booth RE Jr: Harvesting autogenous iliac bone grafts. A review of complications and techniques. Spine 14:1324-1330, 1989

19. Laursen M, Hoy K, Hansen ES, et al: Recombinant bone morphogenetic protein-7 as an intracorporal bone growth stimulator in unstable thoracolumbar burst fractures in humans: preliminary results. Eur Spine J 8:485-490, 1999

20. Magin MN, Delling G: Improved lumbar vertebral interbody fusion using rhOP-1: a comparison of autogenous bone graft, bovine hydroxylapatite (Bio-Oss), and BMP-7 (rh OP-1 ) in sheep. Spine 26:469-478, 2001

21. Paramore CG, Lauryssen C, Rauzzino MJ, et al: The safety of OP-1 for lumbar fusion with decompression-a canine study. Neurosurgery 44:1151-1156, 1999

22. Patel TC, Erulkar JS, Grauer JN, et al: Osteogenic protein-1 overcomes the inhibitory effect of nicotine on posterolateral lumbar fusion. Spine 26:1656-1661, 2001

23. Rawlinson JN: Morbidity after anterior cervical decompression and fusion. The influence of the donor site on recovery, and the results of a trial of surgibone compared to autologous bone. Acta Neurochir 131:106-118, 1994

24. Salkeld SL, Patron LP, Barrack RL, et al: The effect of osteogenic protein-1 on the healing of segmental bone defects treated with autograft or allograft bone. Spine 83:803-816, 2001

25. Sandhu HS, Kanim LE, Kabo JM, et al: Effective doses of recombinant human bone morphogenetic protein-2 in experimental spinal fusion. Spine 21:2115-2122, 1996

26. Sandhu HS, Khan SN, Suh DY, et al: Demineralized bone matrix, bone morphogenetic proteins, and animal models of spine fusion: an overview. Eur Spine J 10 (Suppl 2):122-131, 2001

27. Schimandle JH, Boden SD, Hutton WC: Experimental spinal fusion with recombinant human bone morphogenetic protein-2. Spine 20:1326-1337, 1995

28. Schnee CL, Freese A, Weil RJ, et al: Analysis of harvest morbidity and radiographic outcome using autograft for anterior cervical fusion. Spine 22:2222-2227, 1997

29. Sheehan JP, Kallmes DF, Sheehan JM, et al: Molecular methods of enhancing lumbar spine fusion. Neurosurgery 39: 548-554, 1996

30. Subach BR, Haid RW, Rodts GE, et al: Bone morphogenetic protein in spinal fusion: overview and clinical update. Neurosurg Focus 10 (4): Article 3, 2001

31. Vaccaro AR, Chiba K, Heller JG, et al: Bone grafting alternatives in spinal surgery. Spine J 2:206-215, 2002

32. Ware WE Jr: The SF-36 health survey, in Spilker B (ed): Quality of life and Pharmacoeconomics in Clinical Trials, ed 2. Philadelphia: Lippincott-Raven, 1996, pp 337-345

33. Ware JE, Snow KK, Kosinski M, et al: SF-36 Health Survey Manual and Interpretation Guide. Boston: The Health Institute, New England Medical Center, 1993

Manuscript received October 22, 2002.

Accepted in final form November 20, 2002.

The authors have received grant research support from Stryker Biotech.

Address reprint requests to: Michael G. Fehlings, M.D., Spine Program, Division of Neurosurgery, Toronto Western Hospital, 399 Bathurst Street, West Wing 4-449, Toronto, Ontario M5T 2S8 Canada. email: michael.fehlings@uhn.on.ca. 